\title{
Alternatives for the bulb trade from Turkey: a case study of indigenous bulb propagation
}

\author{
Abigail Entwistle, Sema Atay, Andy Byfield and Sara Oldfield
}

\begin{abstract}
In this paper we describe the outcomes of a 10 -year project that provided an alternative source of material for the international trade in bulbous plants from Turkey. In the mid 1980s the export of wild bulbs was extensive and was considered to be unsustainable. Building on the opportunities for propagation of snowdrops (Galanthus spp.), this project produced bulbs for trade, taking into account provision of local livelihoods and income generation, utilization of existing trade structures, regulation through national legislation, monitoring of overseas suppliers, and customer sensitization. Three villages and over 250 villagers were ultimately involved in bulb propagation. The project demonstrated that bulbs
\end{abstract}

for an international market can be produced within a village environment to meet CITES criteria for artificial propagation. Through the application of rural development, local horticultural training, international legislation, fair-trade, and environmental consumer issues the project also illustrates the complexities of integrated approaches to trade issues. This paper presents in detail the methods used in developing this model for local plant propagation, and highlights the lessons learnt from the project.

Keywords Bulbs, CITES, community conservation, Galanthus, plant conservation, propagation, trade, Turkey.

\section{Introduction}

The trade in plants and animals that have been collected from the wild continues to pose a threat to source populations and natural habitats (Jenkins \& Oldfield, 1992; Oldfield, 1999; Hilton-Taylor, 2000; Roe et al., 2002). Conservation organizations have looked for ways to restrict offtake of such species, and where appropriate to ensure that continued trade can be sustainable (Hutton \& Dixon, 2000). Because international trade is generally driven by foreign demand, cooperative international mechanisms may be required to prevent over-exploitation. The Convention on International Trade in Endangered Species of Wild Fauna and Flora (CITES) provides one of the main frameworks for discussion and action on the sustainability of international trade in individual species. Through the working of the Convention it is widely acknowledged that addressing the threat from trade solely at source may not always protect a species,

Abigail Entwistle (Corresponding author) and Sara Oldfield Fauna \& Flora International, Great Eastern House, Tenison Road, Cambridge, CB1 2TT, UK. E-mail: AbigailFFI@aol.com

Sema Atay DHKD, The Turkish Society for the Protection of Nature, Büyük Postane Cad., No. 43-45, Kat 5-6, Bahçekapi - Sirkeci, 34420 Istanbul, Turkey.

Andy Byfield Plantlife, 1 Elizabeth St., London, SW1W 9RP, UK.

Received 6 December 2001. Revision requested 22 May 2002. Accepted 19 June 2002 and it may be necessary to investigate compliance at all levels of the trade and to sensitize markets (often involving public awareness among potential customers). Furthermore, restriction of trade can also have implications for the welfare and rights of local people, who may rely on the collection of wild products as a source of income, and may consequently affect the values that are placed on the local habitat.

It is clear that a single solution or mechanism is rarely appropriate to situations of overuse, and a holistic approach, drawing together a set of different conservation techniques, is often needed. These may include mechanisms that deal with the root causes of collection at a local level (often poverty, rather than preference) through the provision of alternative livelihoods or food sources, as well as the introduction and enforcement of limits to collection of wild plants and animals. Where applicable, ranching or direct propagation to supply the trade can maintain both income and access to the species.

The Turkish flora is rich both in numbers of species and levels of endemism, and the southern Toros Mountains support at least 2,500 vascular plants, of which 235 are endemic to the area (WWF \& IUCN, 1994). Within Turkey these mountains are the centre for collection of wild bulbs (Read, 1989a, b), and during the 1980s wild stocks of particular bulbous species were increasingly targeted by the horticultural trade (Ekim et al., 1984; Demiriz \& Baytop, 1985). Wild harvesting is 
particularly damaging to bulbous plant populations because it involves removal of the entire plant, leaving no opportunity for further vegetative growth, and is typically conducted prior to seeding, when leaves are still easily visible.

Research by international organizations, including Fauna \& Flora International (FFI), the World Conservation Monitoring Centre (now UNEP-WCMC) and TRAFFIC, highlighted the scale of the trade in wild bulbs exported from Turkey (Plas-Haarsma, 1987; McGough et al., 1989; Oldfield, 1989). By the mid 1980s exports of wildcollected bulbs exceeded 60 million bulbs per year, of which over half were Galanthus spp. (snowdrops). Large numbers of Eranthus hymalis (L.) Salisb (winter aconite), Cyclamen spp. (cyclamen) and Anemone blanda Schott \& Kotschy (windflower) were also exported. These bulbs met public demand for small so-called 'minor' bulbs, particularly popular among consumers in the UK and Germany, and concerns were raised about the long-term effects of collection, particularly given the lack of basic population data (Oldfield, 1989). Furthermore, although most species of Cyclamen and Galanthus in trade were relatively widespread and abundant, rare or locally endemic species were also included in bulk export consignments (Read, 1989a).

Bulbs were collected by Turkish villagers, either in organized parties or on an ad hoc basis (Read, 1989b), and were purchased by bulb export companies. Villagers relied on this as a source of cash, although they received less than $1 \%$ of the final market value of the bulbs (Read, 1989b). Within Turkey the export of bulbs was organized by at most five companies, under a series of government quotas. Most of this trade was then channelled through middlemen in the Netherlands. Bulbs were generally re-exported to the UK, Germany and the US, and many bulbs reached their final markets bearing the misleading label 'Grown in Holland' (Read, 1989b). By the late 1980s village collectors reported that wild bulb stocks were becoming depleted (Read, 1989a, b).

This paper presents a case study of an indigenous bulb propagation project in Turkey, demonstrating both the complexities of a holistic approach and that in situ propagation can offer a realistic alternative to extractive trade. The project aimed to provide the market with an alternative and sustainable source of bulbs, without restricting the incomes of local people or devaluing the natural environment that supports bulb populations. The central theme of the project has been to demonstrate a model of how native plant species could be propagated at a local level using appropriate technologies, and how such products could provide an alternative to wild material, whilst reducing pressure on wild populations in the immediate vicinity.

\section{The Indigenous Propagation Project}

The Indigenous Propagation Project was originally established in 1991 as a response to the high level of exports of wild-collected flower bulbs from Turkey, and the perceived risk to native bulb populations (Read, 1989a, b). It was originally conceived as a pilot project for the development of low technology methods for local growers to produce bulbs that could be classified as truly 'artificially propagated' (sensu CITES Resolution Conf. 2.12 (Rev.) as amended), and to examine whether such products could compete with material from normal commercial cultivation. It was considered that working only within local communities would not in itself ensure success, and that there was a need to engage with stakeholders at all levels in the trade. As well as working to support village-based bulb propagation through horticultural trials and training and capacity building, the project involved marketing of bulbs, liaison with bulb companies, consumer sensitization, and lobbying of the Turkish government and CITES.

\section{Village-based bulb propagation}

In 1993 a first trial site for the project, Dumlugöze, was selected within the Toros mountains. This is a relatively undeveloped village of c. 2,000 people, with restricted sources of local income. The village is located on a north facing hillside at $900-1150 \mathrm{~m}$ altitude. The climate is high mountain Mediterranean, with hot, dry summers and wet winters, frequently with deep snow. A shale substrate supports basic agriculture, including walnut, apple and cherry trees, vegetables and grain. The hillsides are grazed by sheep and goats, with transhumance practised during summer. To supplement subsistence income from agriculture and sale of natural products such as fuelwood, fungi, medicinal plants and orchid roots (from which the traditional drink of salep is made), many of the men leave the village seasonally to work in local towns. The villagers had also previously been involved in the wild-bulb trade, collecting Eranthis, Cyclamen and Galanthus from surrounding hillsides. In 1997 the project was expanded to include two neighbouring villages, Koçašli and Daran. Both of these villages provided suitable growing conditions, although the substrate was freely-draining limestone, making them generally drier than Dumlugöze.

The first propagation trial was limited to Galanthus elwesii (Hook.f.), known to successfully self-divide without needing advanced propagation techniques. This species grew locally, and was one of the main bulbous species exported from Turkey. A high market demand existed for this form of snowdrop (marketed as the 
Turkish giant snowdrop) and it had not proved cost effective to propagate it on a commercial scale in the Netherlands (P. van Leeuwen, pers. comm.). The species was listed as Vulnerable in Turkey (Ekim et al., 1989), was considered as Indeterminate on the 1997 Red List of Threatened Plants (Walter \& Gillett, 1998), but was not evaluated on the 2000 IUCN Red List (Hilton-Taylor, 2000).

After an initial series of briefings in 1993, villagers were given the opportunity to sign up as bulb growers. The number of villagers involved increased from an initial seven to 250 in 2000. Growers were loaned planting material that consisted of small G. elwesii bulbs supplied free of charge by one of the Turkish bulb companies. This material represented the by-product of wild collection, i.e. the bulbs that were too small to be sold commercially. At that time there were no Galanthus in cultivation in Turkey to provide stock for propagation. To maintain bulb stock for sustainable propagation, without planting further wild stock, the bulbs were loaned to growers on the understanding that mother stock would be maintained in their plot, in numbers equivalent to the original planting material supplied to them. This was to be done by replanting smaller bulbs at the time of harvest.

The first planting of $198 \mathrm{~kg}$ of G. elwesii bulbs took place in 1993. Further plantings of by-collection bulbs supported the expansion of the project in subsequent years, but areas were not replanted. Bulbs were planted in spare areas of ground on terraces within the village, in the shade of fruit or nut trees where other crops did not grow. These areas were ploughed, marked rows and furrows were set out, and the bulbs were planted by hand at a depth of $5-7 \mathrm{~cm}$ in autumn (SeptemberOctober). There was limited irrigation after planting, and the plots were weeded and kept free of pests. There was no harvest in the first two years to allow the bulb stock to grow and sub-divide. After three years the planted material had divided successfully to produce daughter bulbs.

The first bulb harvest took place in the late spring of 1996, and on a three-year cycle thereafter. Plants were allowed to seed naturally before harvest in late May of each year. At this time the yellowing leaves remained above the surface, indicating the position of the plants. During the harvest only the larger bulbs were removed. Smaller daughter bulbs were left in place or replanted to provide stock for future propagation. The harvested bulbs were graded, dried on trays, and stored prior to transport. Each year the harvest was marked by a celebration, involving villagers, local dignitaries and media representatives. Bulb production increased from $303 \mathrm{~kg}$ in 1996 to $1,237 \mathrm{~kg}$ (c. 200,000 bulbs) in 2000, reflecting the increase in the number of village growers, the land in cultivation, the bulb stock planted, and natural reproduction of bulbs (Fig. 1). Although the daughter bulbs were not removed for weighing, it is estimated that $8,000-9,000 \mathrm{~kg}$ (c. 750,000 bulbs) of stock is replanted during harvest (S. Atay, pers. obs.). Except for the first year of harvest, the production of bulbs from the fields has ranged from $30-38 \%$ of the original weight of bulbs planted (Morgan, 2000).

Bulbs from the project were sold back to the bulb export company that had provided the original planting material, avoiding any middlemen. The price was negotiated directly with company representatives, with the aim of providing villagers with a fair price, including a premium for propagated as opposed to wild-collected material. By 2000 the price offered per $\mathrm{kg}$ of propagated bulbs included a premium of 1.6 to 2.5 times that offered for wild-collected stock. In 2000 the annual income from bulb production in the villages was c. 3,269 million Turkish Lira (c. US $\$ 5,800$, or $c$. US $\$ 75-90$ per family), approximately twice that from an equal number of wild bulbs. The price paid for the bulbs was also more fair, representing c. $12 \%$ of the final market price, in contrast to $1 \%$ for wild-collected bulbs.

During the project, bulb specialists provided advice on growing conditions, and trials were conducted to investigate ways to improve the propagation techniques used in the village, and thus the quantity and quality of the harvest. Experiments were established in sample plots within the village to assess growing conditions (position and soil type), the best time and depth of planting, possible pre-planting treatments, and the compatibility of bulb propagation with other crops.

Bulbs grew most successfully in areas of well-drained soil, out of direct sunlight. Ideal conditions for the growth of G. elwesii appear to be at altitudes $>1,000 \mathrm{~m}$, on north-facing slopes with gradients of $1-5 \%$. Information from the village-based experiments was incorporated directly into the advice given to villagers. Treatments prior to planting with $10 \%$ sodium hypochlorite and a proprietary fungicide were recommended. The use of twin scaling, a technique of propagation from pairs of bulb scales, was shown to be a potentially important tool to increase productivity (T. Wiltshire, pers. comm.). Experiments also demonstrated that G. elwesii grew successfully alongside wheat, barley and vetch, allowing villagers to maximize income from their land.

Diversification of species and production from seed were also investigated. Seed of G. elwesii can easily be collected from the wild (under licence), as the seed remains in the capsule for some time. Research showed that when fresh (i.e. moist) seed was sown under the correct conditions germination rates were high, but production from seed required considerable care in the first year and this generally proved too rigorous for 

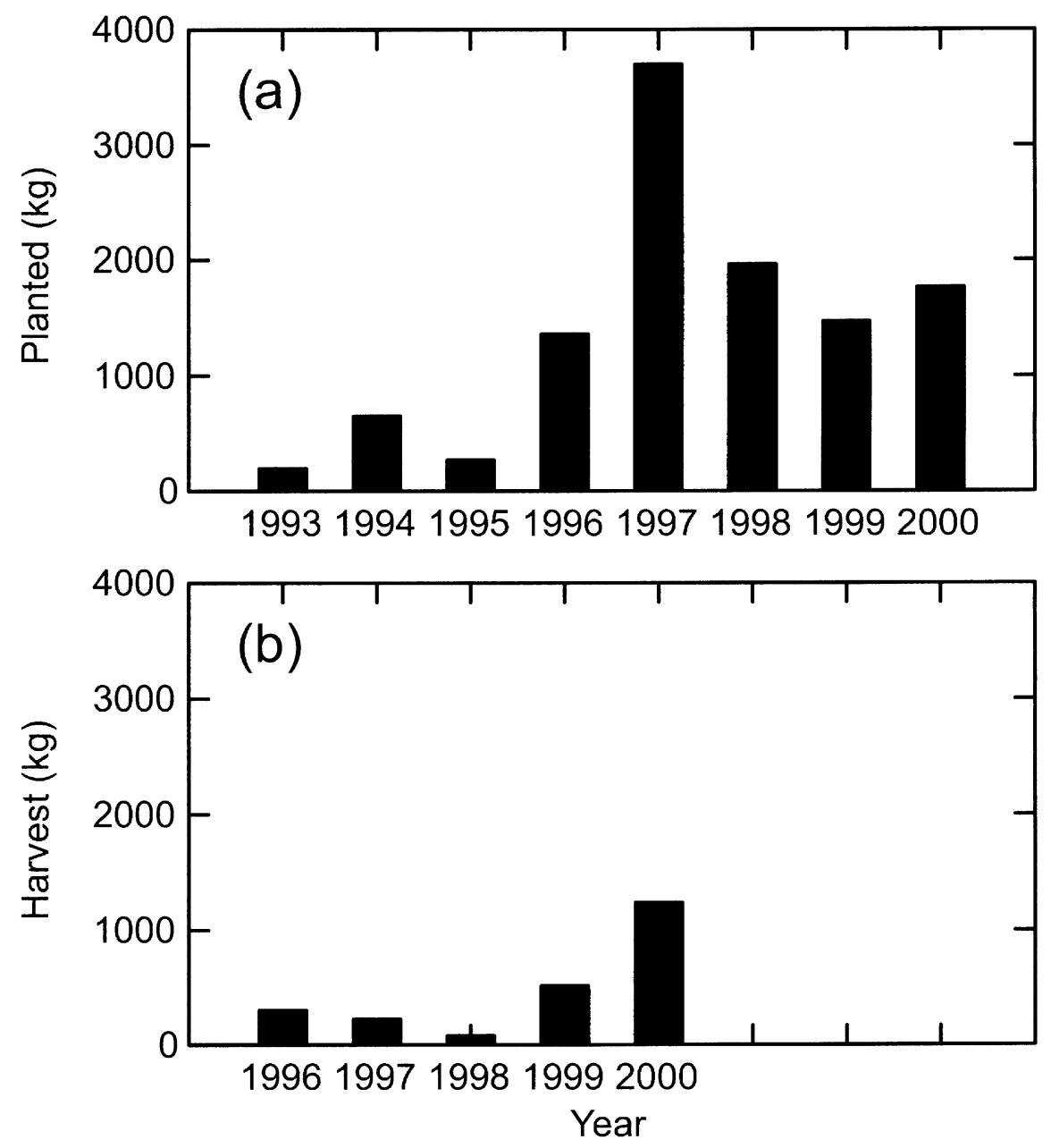

Fig. 1 (a) Weight (kg) of seed bulbs planted each year from 1993 to 2000, and (b) corresponding weight (kg) of bulbs harvested in the third year after planting, from 1996 to 2000. Data collated by Morgan (2000).

village conditions. Furthermore, production of saleable bulbs took at least four years from seed. Production of Eranthis hyemalis from seed was also attempted, but this was less successful than trials of seed-grown Galanthus, because E. hyemalis proved more sensitive to procedures of seed collection, storage and sowing.

Initially, organization of the village bulb growers was conducted relatively informally, but in 1998 social assessments documented existing community structures and identified options for formal organization of bulb growing within the village. A cooperative already existed within the village, and national regulations on such organizations led to the decision to establish a looser 'Bulb Growers Association' to provide an umbrella society for those involved in bulb propagation. This organization was entirely locally-led, with elected representatives, and held information on all bulb growers and their planted stock. The Association gradually took over responsibility for the distribution of planting material, ownership of shared project equipment, organization of the harvest and annual festival, sorting and packing of bulbs, and negotiations over sales and pricing. The Association also liaised with the local Ministry of Agriculture, which registered growers as producers of propagated material, and was given advice on structure and management, as well as training in accounting and communication, and it now has a full-time office within the village.

The villagers were provided with training in skills relating to planting, tending and harvesting bulbs, including methods of pest management and postharvest handling. Initial bulb propagation was supervised to ensure that appropriate methods were used, taking into account the findings of the horticultural 
trials. In 2000 an illustrated manual for bulb propagation was produced to provide a source of reference in support of the long-term sustainability of the project. The continued success in production of bulbs indicates that villagers have developed the basic skills necessary to produce bulbs, although further training (for example in twin scaling) continues to be provided (T. Wiltshire, pers. comm.).

Supporting materials and courses in environmental issues were also produced for local schools. These materials, along with the bulb propagation manual, were disseminated to other villages in the region that were interested in starting similar bulb propagation schemes. Although a number of communities asked to join the propagation scheme, expansion was limited by the availability of planting material.

\section{Marketing of the bulbs}

Commercial buyers in the UK, identified on the basis of established relationships, reputation (including policies of ethical sourcing of material), and their ability to clearly brand the bulbs, were informed of the opportunities to market bulbs from the project. Because Turkish export regulations require bulbs to be sold through certified exporters, relationships were established between UK companies and the Turkish exporter.

In the UK the bulbs were sold as 'conservation grade' from a fairly traded source, mainly through catalogue sales, where an explanation of the bulbs' provenance could be presented. The bulbs were also promoted through parallel public awareness campaigns focusing on the wild bulb trade and the Turkish village project. The bulbs were sold, through two suppliers, for a price above that charged for either wild-collected bulbs or G. nivalis from the Netherlands. In 1999 the demand for this product outstripped supply, and the bulbs sold out early in the sales season (R. Massey, pers. comm.). Reports from customers and retailers indicated that the bulbs flowered well once transplanted to gardens in the UK, and were considered to be healthy and in good condition relative to wild-collected stock (R. Massey, pers. comm.).

To address the bulb trade at a wider level, and to develop an appropriate market for bulbs from the project, environmentally responsible attitudes towards the sourcing and labelling of bulbs were promoted among retailers and suppliers. In the early 1990s changes in corporate culture in the UK and the growing recognition among the business community of the importance of environmental concerns both to their customers and their brand image (Reynolds, 1999) provided a basis for engagement. It was recognized that a non-governmental organization (NGO) could offer opportunities to the bulb industry, rather than taking a purely confrontational approach, and could work in partnership with them to bring about change. Collaboration with bulb companies focused not only on promoting the sale of bulbs from cultivated sources, but also on clarifying the source of bulb material through accurate labelling.

A voluntary certification scheme was developed, enabling bulb retailers and wholesale suppliers to commit either to never knowingly sell wild bulbs (category A) or to label any wild bulbs they sold as 'from a wild source' (category B). Companies who signed up to either category were listed in The Good Bulb Guide, a publication produced annually (and later biennially) by FFI. The Good Bulb Guide was distributed directly to horticulturalists, gardeners, gardening organizations, and the general public, and was supported by extensive media coverage and listings in the gardening press. Such promotion offered increased exposure, and thus a potential competitive advantage, for those companies publicly committing to more environmentally responsible policies.

Compliance with the commitments in The Good Bulb Guide was monitored each year, latterly in conjunction with the Cambridge University Botanic Garden. Bulbs were purchased from catalogues and retail outlets, labelling was checked, and bulbs labelled as cultivated were examined and then grown to check the claims made in The Good Bulb Guide. If suppliers continued to stock suspect bulbs after being alerted to a problem in their supply, they faced the risk of public exclusion from The Good Bulb Guide in the following year.

By 2000, listings in The Good Bulb Guide included 57 companies (49 and 8 in categories A and B, respectively), including almost all of the major names in this industry. A number of high profile companies publicly changed their policy on the sale of wild bulbs during this time (e.g. Winchester Growers press release, 1997), and moved from category B to A. Relatively few infractions of the commitments made in The Good Bulb Guide were detected. Over a 5-year period 19 investigations were carried out into companies who appeared to be erroneously selling wild bulbs labelled as cultivated stock. In only one case was it necessary to publicly identify a company for breach of its commitment in The Good Bulb Guide.

In the UK public awareness programmes were used to meet two goals within this project: to increase awareness of the threats posed by the wild bulb trade to native plant populations, and to develop market interest in propagated bulbs from the project site. Awareness campaigns used the media to highlight the role the gardening public could play in conserving wild bulb populations. Consumers were encouraged to be selective in the bulbs they bought, request further information 
on the origin of bulbs, use The Good Bulb Guide as a source of information, report companies selling mislabeled wild bulbs, and buy bulbs originating from the project site.

Although no structured monitoring of people's attitudes on this issue was conducted, anecdotal evidence suggests that the wild-bulb trade became a betterrecognized consumer issue as a result of the extensive publicity. This was also reflected in the public stance taken by certain bulb companies on this issue, and might have contributed to the reduction in wild material offered for sale.

\section{Liaison with government and CITES}

To reduce pressure on wild populations of bulbous plants and to ensure that bulbs from the project were recognized as 'artificially propagated' the Turkish government was lobbied to ratify CITES, which lists all species of Cyclamen and Galanthus on Appendix II. The Convention came into force in Turkey in 1996. In 1999 the adequacy of the scientific assessments and enforcement of CITES regulations in Turkey were reviewed, and the export quotas and controls in place were considered sufficient to ensure a sustainable trade (Fauna \& Flora International, 1999; EU Scientific Review Group, 2001).

\section{Discussion}

One of the challenges faced by this project was the production of bulbs to meet CITES criteria for artificial propagation, which would therefore be treated separately from wild-collected material for export quotas. CITES defines artificial propagation as 'plants grown from seeds, cuttings, divisions, callus tissues or other plant tissues, spores or other propagules under controlled conditions' (CITES Resolution Conf. 9.18). 'Under controlled conditions' is further defined as 'in a non-natural environment that is intensively manipulated by human intervention for the purpose of producing selected species or hybrids', and cultivated parental stock used for artificial propagation must be 'established and maintained in a manner not detrimental to the survival of the species in the wild, and managed in such a way that long term maintenance of this cultivated parental stock is guaranteed'. One of the key issues for the project was to determine whether village-grown bulbs would be classified as 'artificially propagated' rather than as 'grown on' (i.e. wild transplanted). Wild transplantation is a practice by which undersized wild harvested bulbs are replanted in fields and left to grow to full size over a period of one to two years prior to export. In this time bulbs typically do not produce offset daughter bulbs, and are therefore generally considered as a subset of wild-collected material.

In contrast to wild transplantation, the current project left bulbs in the ground for a third year, so that each bulb produces on average one daughter bulb. Assuming that for each bulb sold an equal or greater quantity is retained as productive mother stock, thereby eliminating the need to return to the wild for new planting material, the process meets the CITES definition of artificial propagation. However, the area of cultivation in this project was within the bulbs' natural habitat (and therefore failed to meet the 'non-natural' caveat in the CITES definition), and CITES officials also questioned the extent to which the environment was 'manipulated' for cultivation as this project relied on only ploughing of the area and low technology maintenance. Despite these questions, the Turkish CITES Technical Committee has now recognized the bulbs from Dumlugöze and the other project sites as being artificially propagated.

\section{Impacts of the project}

The project has had greater than expected consequences for villagers in Dumlugöze and the other project villages. Bulb growers have developed new horticultural and business skills as a result of the project, and villagers have generally indicated an extremely positive perspective of the project, were satisfied that the premium paid for cultivated bulbs made the effort of propagation worthwhile, and welcomed the price paid for bulbs as important income (Morgan, 2000). Further unexpected benefits have resulted from media attention and subsequent wider interest in the village, in the form of increased investments by government in local infrastructure, such as improvement of roads. The development and implementation of the project involved women from the community, and the skills learnt have now been adapted to support a range of complementary income-generating activities, reflecting increasing levels of self-determination within the community (Morgan 2000).

This project has demonstrated an alternative mechanism to supply a good-quality source of bulbs that were traditionally taken from the wild. The feedback from customers appears to reinforce the view that propagated material is generally more successful in gardens than wild-collected material and is more likely to be pest-free (Read, 1989a). However, the production of sufficient material to supply the trade remains a challenge, and existing cultivation sites will not be able to meet the growth in demand. In 2001 the harvest from the project was much lower than anticipated, apparently 
as a result of the poor quality of planting material supplied in 1998. However, despite these limitations, we consider that the project represents a model for other similar initiatives.

The project also affected the attitudes of UK bulb companies towards the sale of wild bulbs. A recent review of bulb companies listed in The Good Bulb Guide indicated that they supported this approach to labelling (FFI, unpub. data), and recognized that the Good Bulb Guide promoted good practice within the industry. However, it is not clear how far attitudes of bulb exporting companies within Turkey have been affected, beyond the identification of new opportunities linked to village propagation. At present, relationships with bulb companies are limited to the UK. Attempts to develop a complimentary US Good Bulb Guide in 1996, in partnership with the American Horticultural Society, proved less successful, perhaps due to the lack of pre-existing dialogue between NGOs and bulb companies there.

Given the opportunities for propagation, wild collection of bulbs appears to be less rewarding for villagers, although members of the community who have not been involved in the propagation scheme still take bulbs from the wild (Morgan, 2000). The scale of the current project cannot produce sufficient bulbs to completely relieve the pressure on wild populations, but the changes in the bulb market and the restriction of national quotas over the same period have significantly reduced demand for wild bulbs, particularly as a result of the ratification of CITES by the Turkish government. By 1997 annual exports of Galanthus elwesii had dropped to 5.5 million bulbs, from a figure of 25.6 million in 1990 (Fauna \& Flora International, 1999).

\section{Lessons learnt from the project}

The project has demonstrated a model for plant propagation for trade within a village environment, providing a source of local income based upon local natural resources. Community ownership of bulb propagation was achieved, underpinned by increased skills among villagers. The project was supported by effective partnerships with the bulb retailing industry and a market opportunity for conservation-grade bulbs. However, the project required a longer timescale, and greater investment, than anticipated at the outset, and investment in the project is not currently matched by the resulting bulb sales. At the current scale of bulb production from the project it remains questionable whether commercial viability has been achieved. The future rate of market growth for propagated bulbs is unclear, particularly given uncertainty in harvests and new regulations controlling the export of wild-collected bulbs from Turkey. However, the project has proved successful in demon- strating alternative sources of a resource traditionally taken from the wild.

\section{Factors influencing success of the project}

We identified a number of factors that assisted the success of this project, and that should be taken into account if the model were to be applied elsewhere:

- G. elwesii was a suitable species because it occurred locally, was relatively easy to cultivate within the villages, had a short generation time and thus provided an early return, and had not been successfully cultivated in the Dutch bulb fields, giving local propagation a competitive advantage.

- There was a supportive cultural context, with a local tradition of using bulbs as a source of income, recognition of the increasing difficulties of locating wild bulbs for sale, and influential individuals within the village recognizing the potential offered by the project and the opportunity to develop an alternative source of income for their families.

- Both risks and costs were low because bulb growers needed to make little investment, apart from time, propagation used otherwise unproductive land and could be integrated into a multi-use agricultural system, and overall propagation involved less effort than wild collection.

- Political support from local politicians and administrators reinforced the project's standing at a local level, ensured that growers were assisted by the local Ministry of Agriculture and, as an unexpected benefit, media attention secured further government investment in the region.

- Bulb export companies were supportive, recognizing the changing situation and the opportunities presented by collaboration with the project, and were willing to offer both planting material and a premium price for the product.

- The demand for bulbs was sufficient to support the trade, and efforts to highlight the need for appropriate sourcing and labelling of bulb material were successful in influencing public opinion and demand, as well as changing the behaviour of bulb companies.

- The bulbs were considered better quality than wild material and met the appropriate CITES criteria.

In contrast, a number of factors hindered the project and, where appropriate, required direct intervention:

- The lack of a formal socio-economic assessment at the start of the project meant that we had an incomplete understanding of village structures.

- The planting material provided was of a relatively poor quality, and the species of bulbs supplied could not be determined at the time of planting. 
- The returns in the first year of harvest were low relative to the quantity of material planted.

- The villagers were occasionally impatient to wait three years for a crop.

- There were difficulties in tracking the chain of custody of bulbs through the exporting systems to avoid contamination with other stock.

- There was a lack of direct business involvement and investment early in the project.

- There were fluctuating and unpredictable production levels, which destabilized market demand.

- There was a limited availability of planting material left over from wild-collection, restricting the rate of expansion of the project.

\section{Wider implications of the indigenous propagation model}

From the outset the project was envisaged as a model that could be replicated elsewhere, both for bulbs and other horticultural plants such as cacti, cycads and palms, and also for medicinal and herbal species (Read, 1993). However, replication to other groups of plants has been limited, and may be most relevant to the trade in medicinal rather than horticultural plants, given that there is existing well-established industrial production of house and garden plants in developed countries. Bulbs continue to be collected from the wild in China, USA and former Soviet states (Oldfield, 1999).

Within Turkey the project stimulated interest and discussion amongst the bulb trade as a whole, and although bulb exports continue to be predominantly wild-collected or wild-transplanted, there has been a substantial increase in the development of propagation initiatives (Fauna \& Flora International, 1999). However, although wild collection is now better managed (Fauna \& Flora International, 1999), there is still a lack of scientific information on the long-term effects of prolonged collection of wild bulbs. In this context the development of different production alternatives is in line with the precautionary principle for conservation. Indigenous propagation offers a means by which the needs of the local population can be met, while reducing the pressures on populations of commercially important plants.

\section{Acknowledgements}

The Indigenous Propagation Project was part of a partnership programme for plant conservation in Turkey operated by Fauna \& Flora International and DHKD (The Turkish Society for the Protection of Nature). The project was originally developed in collaboration with the Plants Programme of WWF-International, which provided the initial financial support. Since then the project has been supported by the Stanley Smith Horticultural Trust and by a grant from the National Lottery Charities Board. Many individuals have contributed to the success of this project. The original concept for the project was developed by Mike Read and we owe much to his foresight and enthusiasm in developing this work. In particular we would like to thank Professor Neriman Özhatay, Vedat Ulug, Nigel Coulson, Vicky Morgan, Alan Hamilton, Professor John Parker, Alan Vaughan and Richard Massey of Unwins, John Shipton, and Trevor Wiltshire. We would like to thank all the villagers for their commitment to this project, and would like to highlight the enthusiasm of Gülbaz Palaz in promoting bulb propagation at a local level. The personal concerns of Mrs Russell Arundel and Mrs Jocelyn Sladen for the conservation of Turkish plants have been an inspiration to the project.

\section{References}

Demiriz, H. \& Baytop, T. (1985) The Anatolian Peninsula. In Plant Conservation in the Mediterranean Area (ed. C. GomezCampo), pp. 113-121. W. Junk, Dordrecht, Netherlands.

Ekim, T., Koyuncu, M., Erik, S., Güner, A., Yildiz, B. \& Vural, M. (1984) Taxonomic and Ecological Investigations on the Economic Geophytes of Turkey. Research project TBAG, 490A, Ankara, Turkey.

Ekim, T., Koyuncu, M., Erik, S. \& İlarslan, R. (1989) List of Rare, Threatened and Endemic Plants in Turkey. Turkish Association for Conservation of Nature and Natural Resources, Ankara, Turkey.

EU Scientific Review Group (2001) Conservation and Cultivation of Traded Geophytes in Turkey and Georgia, Executive Summary. Document SRG17/4/2, Scientific Review Group of the EU, Brussels, Belgium.

Fauna \& Flora International (1999) CITES Significant Trade in Appendix II Species (Plants). Review of Trade in Galanthus and Cyclamen in Turkey and Georgia. Report prepared for the CITES Secretariat by FFI in association with DHKD and WWF Georgia. Fauna \& Flora International, Cambridge, UK.

Hilton-Taylor, C. (compiler) (2000) 2000 IUCN Red List of Threatened Species. IUCN, Gland, Switzerland and Cambridge, UK.

Hutton, J. \& Dixon, B. (2000) Endangered Species, Threatened Convention. Earthscan, London, UK.

Jenkins, M. \& Oldfield, S. (1992) Wild Plants in Trade. TRAFFIC International, Cambridge, UK.

McGough, H.N., Mathew, B.F., Peter, H., Read, M., Wertel, N. \& Wijnands, O. (1989) A Report on the Status and Cultivation of Cyclamen and Other Species of Geophytes in Turkey. Paper prepared by Scientific Working Group of the EC CITES Committee, CITES, Geneva, Switzerland.

Morgan, V. (2000) Indigenous Propagation Project - Independent Review and Evaluation. Unpublished report. Fauna \& Flora International, Cambridge, UK.

Oldfield, S. (1989) Bulb Propagation and Trade Survey - Phase II. Unpublished report. Wildlife Trade Monitoring Unit, World Conservation Monitoring Centre, Cambridge, UK. 
Oldfield, S. (1999) Collected wisdom. The Garden. Journal of the Royal Horticultural Society, 124, 700-704.

Plas-Haarsma, van der M. (1987) Cyclamen in Trade. TRAFFIC Rapport 5. TRAFFIC, Zeist, The Netherlands.

Read, M. (1989a) The bulb trade - a threat to wild plant populations. Oryx, 23, 127-134.

Read, M. (1989b) Grown in Holland? Fauna \& Flora Preservation Society, Brighton, UK.

Read, M. (1993) The Indigenous Propagation Project: a search for co-operation and long term solutions. In Species Endangered by Trade - A Role for Horticulture? (eds M. Groves, M. Read \& B.A. Thomas), pp. 54-62. Fauna \& Flora Preservation Society, London, UK.

Reynolds, J. (ed.) (1999) Environmental Responsibility in World Trade: Conference Publication. The British Council with WCMC and IIED, London, UK.

Roe, D., Mulliken, T. Milledge, S., Mremi, J., Mosha, S. \& Grieg-Gran, M. (2002) Making A Killing or Making a Living: Wildife Trade, Trade Controls and Rural Livelihoods. IIED Biodiversity and Livelihoods Issues No 6, IIED, London, UK.

Walter, K.S. \& Gillett, H.J. (eds) (1998) 1997 IUCN Red List of Threatened Plants. World Conservation Union, Gland, Switzerland and Cambridge, UK.

WWF \& IUCN (1994) Centres of Plant Diversity. A Guide and Strategy for their Conservation. Volume 1. IUCN Publications Unit, Cambridge, UK.

\section{Biographical sketches}

Dr Abigail Entwistle is currently the Director of Eurasia Programmes at Fauna \& Flora International (FFI). She was the project manager for the Indigenous Propagation Project and the Good Bulb Guide from 1996, and continues to have a strong interest in issues relating to sustainable use.

Sema Atay has been involved in nature conservation since 1992 when she first joined DHKD (The Turkish Society for the Conservation of Nature) for The Indigenous Propagation Project of Threatened Turkish Bulbs. She has been involved in many different aspects of plant conservation during her time with the Society.

Andy Byfield worked on plant conservation projects in Turkey for 10 years on behalf of FFI, and is co-author of the forthcoming publication, Important Plant Areas of Turkey. Currently he works for the UK plant conservation charity Plantlife, developing their species recovery programmes for some of Britain's rarest plants.

Sara Oldfield is Director of Global Programmes at FFI. She has a long-standing interest in international plant conservation, and carried out the first comprehensive study of the international trade in wild flower bulbs 15 years ago. 